\title{
An Overview of the Athlete's Biological Passport (ABP) in Professional Road Cycling and causes of natural variation within the ABP
}

\author{
Rory Nolan ${ }^{1}$, Richard Usher ${ }^{1}$, Neil Heron ${ }^{2,3} \bowtie$
}

\begin{abstract}
This article provides an overview of the athlete's biological passport (ABP) within professional sport, with a particular focus on professional road cycling. We describe the rationale behind the ABP, what is recorded on it (particularly focusing on the haematological passport), what can cause 'natural' variations to it and discuss its role within professional sport. These 'natural' variations often occur at Grand Tours but more research is required into what happens during these multiple-stage road cycling races in terms of the ABP.
\end{abstract}

Keywords: Athlete biological passport, natural variation

\section{$\bowtie$ Contact email: nheron02@qub.ac.uk (Neil Heron) \\ ${ }^{1}$ East Cheshire NHS Trust, Victoria Road, Macclesfield, Cheshire, SK10 3BL, UK \\ ${ }^{2}$ Centre for Public Health, School of Medicine, Dentistry and Biomedical Science, Queen's University Belfast, Room 01012, Institute of Clinical Science B, Royal Victoria Hospital, Grosvenor Road, Belfast BT12 6BA, UK \\ ${ }^{3}$ Centre of Primary Care, Keele University, Staffordshire, England.}

Received: 01 February 2019. Accepted: 13 November 2019.

\section{Introduction}

As defined by the World Anti-Doping Agency (WADA), doping includes the use, attempted use or "presence of Prohibited Substances, Metabolites or Markers in an Athlete's Sample" (1). To the everyday person, doping would be described more in terms of the use of a prohibited drug or method to improve an athlete's performance.

It is a well-known and disappointing fact that illegal doping has been common within professional sport and cycling for almost as long as sport has been in existence. From the late 1800 s, riders would use substances such as alcohol, caffeine or cocaine to reduce the feeling of fatigue (2). As science progressed and the sport grew, riders have gone to new lengths in an attempt to gain a competitive margin over their rivals, a practice that would ultimately cost some men their lives (3).

The doping landscape changed dramatically in the late 80 s and early 90 s with the introduction of Recombinant Human Erythropoietin (rHuEPO) and its potential to increase performance by $10-17 \%$ (3). However, it wasn't until the 2012 United States Anti-Doping Agency (USADA) report about the world's most famous cyclist, Lance Armstrong, that doping in sport came to a very public head (3)(5).
Throughout this whole period, the global cycling governing body, Union Cycliste Internationale (UCI), as well as world and national anti-doping organisations were attempting to come up with new methods of testing to catch those doping and punish those who were caught. These tests would often consist of a urine or blood sample that would then be sent off for analysis. As the science behind doping evolved, the detection tests had to as well, but they were always a step behind. To try and counteract this, in January 2008 the UCI introduced individual Athlete Biological Passports (ABPs) (6), involving the repeated collection and analysis of an athlete's blood and urine results both in- and out-ofcompetition to establish their 'normal' parameters. In 2018, the Cycling Anti-Doping Foundation (CADF), on behalf of the UCI, collected more than 15,000 samples, making it the largest anti-doping program in sport (7). During the same year, 28 athletes were handed bans by the UCI for doping offenses (8).

The ABP runs simultaneously with anti-doping testing, which is attempting to directly identify the presence of banned substances or methods (9).

This article aims to explain the rationale behind the $\mathrm{ABP}$, what is recorded on it and what can cause natural variations to it. Further, we will discuss the potential impact that ethnicity and nationality has on the ABP and if the ABP has been successful in what it set out to do, that is "to eliminate doping from cycling" (6).

\section{The Athlete Biological Passport}

Between WADA and the UCI it was decided that the UCI would become the first international sports federation to pilot the ABP in 2008 (10). As described by the UCI, the ABP is an:

"individual, electronic record for each rider, in which the results of all doping tests collected... over a period of time are collated." (6) 
Although other methods are available, the ABP remains the primary method of detecting autologous blood transfusions used by anti-doping agencies (11).

This broad statement encapsulates the whole ABP, however the Passport itself is broken down into more discreet sections: (6)

1) Urine anti-doping test results;

2) Blood anti-doping test results;

3) Haematological profile;

4) Steroid Profile.

This paper focuses on the haematological profile within the ABP. Cyclists provide daily information on their whereabouts via ADAMS (Anti-Doping Administration and Management System, an anti-doping administrative database administered by World Anti-Doping Agency, WADA) to facilitate this random sampling. A new cyclist entering the system has to undergo tests before they are eligible to be entered into a World Tour event and over the season, a cyclist will be tested a minimum of 2-3 times (12). In January 2019, there were over 1,100 professional cyclists registered with the UCI's ABP testing pool (13).

Using urine and blood tests has been the benchmark for anti-doping initiatives since they were introduced in the 1960s. These testing methods usually looked directly for traces of banned substances or their metabolites within the rider's samples. Although achieving some level of success, riders used many methods in an attempt to 'beat the system.' Methods ranged from riders dropping out of races when they knew they would be tested at the finish, to concealing synthetic bladders filled with clean urine to provide for analysis. Further, the anti-doping agencies were often one step behind the doping regimes, as new doping agents became available well before detection tests (3).

With the introduction of the haematological profile in 2008 , it allowed the anti-doping authorities to use the "concept of indirect detection" (6). Indirect detection relies on looking for changes to certain biomarkers as an effect of the doping, rather than finding evidence of the substance itself (as is the case for direct detection.) (14). Indirect detection was not a totally new concept to the world of professional sport. When introduced prior to the 2000 Olympics, the first test for rHuEPO relied on both direct and indirect detection (15). This was achieved by a urine sample being used to look for direct evidence of the rHuEPO, whilst the blood test looked at haematological markers that were indicative of the use of rHuEPO without looking for the rHuEPO itself (15). In April 2001, the UCI introduced a urine only test for rHuEPO, which was then adopted by WADA in 2002 (3). This urine only test again was a direct detection method, using an isoelectric and double-blotting technique to detect the characteristic pattern of rHuEPO (15). As doping methods changed, especially with regards the ability to detect autologous doping, indirect methods of detection have become more prevalent.

\section{The Haematological Profile}

For a number of years before the introduction of the $\mathrm{ABP}$, the UCI had been measuring haematological parameters of riders tested in-competition. Although there is a huge amount of information available from a Full Blood Count, the primary parameters measured are Haematocrit; the volume percentage of red blood cells in blood, Haemoglobin $(\mathrm{Hb})$; the oxygen carrying compound in red blood cells and percentage reticulocytes (ret); immature red blood cells (16). These parameters are then used to calculate the stimulation index, more commonly known as the OFF-Score (OFFs) (17).

\section{The OFF Score}

The OFF score was devised by Gore et al. in 2003 whilst looking into the ability to detect the use of rHuEPO using a haematological model. The trial gave a number of subjects doses of either rHuEPO or a placebo and measured a number of blood markers. The team then went about developing four "scores" by which they could compare results with. All the scores used equations related to haemoglobin (h), erythropoietin (e), reticulocytes (r) and serum transferrin receptor (s), to create a single figure that could be used for analysis (18). The team also looked at the worst-case scenario scores for each equation for a normal individual at sea level and at altitude. By using the scores of the placebo group and worst-case scenario scores, the team were able to produce a range of scores within which most normal individuals would score (18).

Once the range had been calculated, the scores of the athletes who had been administered rHuEPO were plotted to see if the use of rHuEPO could be detected. Once completed, it was found that an OFF score had the sensitivity to catch an athlete using, or who had recently used, rHuEPO of up to $80 \%$. The same score had a false positive rate of 1 in 1000 (18). These results proved that it was possible to use a haematological model to detect blood doping and created the backbone for the ABP. The equation decided on for use in the $\mathrm{ABP}$ is below:

$$
\text { OFF Score }=H b[g / L]-60 * \sqrt{\operatorname{Ret}}[\%](18)
$$

By including both haemoglobin and reticulocytes within the OFF Score equation, a variation for any reason with either of those will have an impact in the overall score. This is very significant when looking at natural variations that can affect the ABP later on.

\section{Individual Parameters}

The work by Gore et al used parameters determined by a standard population but the UCI and WADA decided to introduce individual parameters in an attempt to make the ABP more sensitive. To help understand this, it is possible to use the example of an individual's weight. Globally, the average weight of a human is between $60 \mathrm{~kg}$ and $80 \mathrm{~kg}$. Using the same idea as Gore et al, this would set the parameters of normal between 60 and $80 \mathrm{~kg}$. However if an individual is weighed on a number of occasions and is found to weigh between 71 and $73 \mathrm{~kg}$, these figures could then be used to create more specific 
parameters for this individual. Therefore, in a scenario whereby the above individual was weighed at $76 \mathrm{~kg}$, using the global parameters this would appear as a normal, however it would be flagged as abnormal on their more specific individual parameters.

The UCI use a similar idea with the ABP. Through testing athletes on a number of occasions, they create individual parameters for each athlete. As more tests are conducted and added to the system, the parameters become closer together over time, as, in theory, the athlete's blood markers should remain relatively stable. Through the use of individual parameters, the sensitivity of the passport increases, but the false positive rate should remain the same. The UCI have not released the equation they use to determine individual parameters (19).

\section{Variations to an ABP}

As the previous illustration shows, even a normal ABP demonstrates a degree of variation and this next section reviews the natural variations within the ABP. The 'Natural' section covers situations that professional riders face within their training and everyday life, such as being at altitude, illness, injury and dehydration and they may wish to document these factors on any antidoping forms.

\section{Natural Variations Altitude}

At sea level, the concentration of oxygen in air is around $21 \%$. As altitude increases, the air thins, meaning by the time an individual is at 3,000 metres above sea level (the height of some Alpine passes used in the Tour de France) the concentration of oxygen falls to little over $14 \%$. This trend continues as altitude increases, meaning by the time an individual reaches the summit of Mount Blanc ( $4877 \mathrm{~m}$ ) concentrations are down to $11 \%$, falling to an uninhabitable $7 \%$ by the top of Mount Everest $(8839 \mathrm{~m})$ (20).

With acute exposure to altitude, the reduction in oxygen concentration in the air can have marked effect on even healthy individuals. For example, at sea level it can be expected a professional cyclist would have a blood oxygen saturation $\left(\mathrm{SaO}_{2}\right)$ of $98-100 \%$, however this will probably fall to around $89 \%$ at $3,000 \mathrm{~m}(21)$. This in turn has an effect on riders $\mathrm{VO}_{2 \max }$, with the $\mathrm{VO}_{2 \max }$ declining $1 \%$ for every $100 \mathrm{~m}$ climbed above $1500 \mathrm{~m}$. Therefore, someone acutely exposed to an altitude of $3,000 \mathrm{~m}$ could expect to see a reduction in their $\mathrm{VO}_{2 \max }$ of around $15 \%$ (21). These acute changes have no effect on a rider's $\mathrm{ABP}$, however there are two situations with regards to altitude that can have an effect.

\section{Training at Altitude}

Although the effect of being at altitude can have a drastic negative impact on a riders $\mathrm{SaO}_{2}$ and $\mathrm{VO}_{2}$ max , instead of trying to avoid it, riders spend weeks training at altitude and thousands of pounds on special tents to simulate being at altitude. As stated above, the concentration of oxygen at altitude is lower than that at sea level, which causes a reduction in the individuals $\mathrm{SaO}_{2}$. This causes a number of changes to occur within the body, the most significant being an increase in haemoglobin concentration, and therefore the blood's oxygen carrying capacity (21). This increase in haemoglobin is caused by two things; firstly a decrease in plasma volume, and secondly an EPO mediated increase in haematopoiesis, triggered by the kidneys recognising the hypoxic state (21). It takes a couple of days for an individual to become acclimatised to the high altitude but the process begins within the first few hours of exposure. A study compared the EPO levels of 26 elite runners at sea level and at an altitude of $2500 \mathrm{~m}$. After just 20 hours at this altitude, the athletes' EPO level had almost doubled (increase of $8.0 \pm 4.7 \mathrm{ng} \mathrm{ml}^{-1}$ ) from $8.6 \pm 2.6 \mathrm{ng} \mathrm{ml}^{-1}$ to $6.6 \pm 4.4 \mathrm{ng} \mathrm{ml}^{-1}$. The same study also concluded that this affect was caused by mechanisms "down-stream from the lungs", more specifically the EPO production cells in the kidney (22). Through its methods of action in haematopoiesis, the increased level of EPO will firstly cause an increase in reticulocyte percentage, followed by an increase in haemoglobin. As these are the two markers used for the generation of the OFF-score, these variations can have a profound effect on the athlete's ABP.

A study involving elite swimmers training at altitude for four weeks illustrated just how dramatic an effect altitude can have on the athletes ABP. After the training block, 6 of the 10 athletes had exceeded the $99 \%$ confidence interval used to detect doping in an ABP. Out of these 6 , some of the thresholds were broken in the following ways:

- 2 exceeded their OFF-score threshold at day 7;

- 1 exceeded their OFF-score threshold at day 28;

- 1 exceeded their Ret\% at day 14 (23).

In the control group of 10 swimmers training at sea level, none of them breached any ABP threshold. The report also mentioned how these effects can still be seen up to 4 weeks after returning to sea level (23). This all highlights the effect altitude training has on all areas of the ABP and how it is essential for all riders being tested by anti-doping agencies to mention any altitude training blocks that they have recently completed.

The reduced concentration of $\mathrm{O}_{2}$ at altitude also causes changes to how oxygen binds to haemoglobin, a process illustrated by Oxygen Dissociation Curves, but these will not be covered in this article.

It should also be highlighted that even after acclimatisation has occurred, the $\mathrm{VO}_{2 \max }$ of a rider is still greatly reduced at altitude, meaning training can often not be at the same intensity as that at sea level. This has led to idea of "Sleep high, train low" whereby an athlete lives above $2,500 \mathrm{~m}$ but descends to below $1,250 \mathrm{~m}$ to train, in the hope to gain benefits from both environments (21).

\section{Genetic Adaptation to Altitude}

Although the majority of the world's population would need to travel to expose themselves to high altitude living, there are 3 population groups that have inhabited high altitude (above $2500 \mathrm{~m}$ ) locations for generations. These population groups can be found in the Himalayas, 
the high lands of Ethiopia and the Andean population of South America. Through centuries of high altitude exposure, these populations have undergone genetic changes that allow them to survive in these harsh environments. For example, both Ethopian and Andeans are known to have elevated haemoglobin levels compared to those living at sea level and the genetic research behind this and other adaptations is ongoing $(24,25)$. These changes need to be understood in case they have a direct impact on the ABP of these individuals.

Currently, with regards to cycling, the area of most interest is the Andean population of South America, and more specifically the cycling hot-bed of Colombia. One of the leading professional riders at the moment is Colombian rider Egan Bernal, who was born in Bogota, located at an altitude of $2644 \mathrm{~m}$ above sea level (26). To survive, and train at a high enough level to be in the top bracket of professional cyclists, riders like Bernal may have genetic adaptations to compensate for the harsher environment they live in. Most noticeably it has been described that Andean populations have higher haematocrit and haemoglobin concentrations, thus increasing the oxygen carrying capacity of the blood to offset the reduced oxygen concentration in the atmosphere (24). These adaptations mean the Andean population are less stressed by hypoxia at higher altitudes; having an $\mathrm{SaO}_{2}$ of around $92 \%$ at an altitude of $4,000 \mathrm{~m}$ compared to closer to $85 \%$ for an individual who usually lives at sea level being exposed to that altitude. The Andean population also have a much greater Arterial $\mathrm{O}_{2}$ content, with a level $16 \%$ higher than the sea level reference (27). When an individual with these adaptations races at sea level, it is of little surprise that their increased oxygen carrying capacity improves their performance, however over time these individuals "acclimatise" to the lower altitude and the advantages are lost (27). What these genetic adaptations do mean, however, is that these riders can train at a much greater intensity at altitude, thus not requiring a "sleep high, train low" method discussed above.

With regards to the ABP, these adaptations can cause some issues. Firstly, the genetic adaptations are not universal for all communities living at altitude, with the Ethiopian and Tibetan populations showing different mechanisms to survive (27). Secondly, the effect of the adaptations on the ABP is not wholly understood to date, which can lead to problems arising. Through the use of the individual parameters on the ABP, it is hoped any genetic variations are accounted for, but with the propeloton featuring riders from more areas of the world, further research may still be needed in this area.

\section{Injury}

Crashes and injuries are an unfortunate part of any professional cyclist's career, so it is important to look at the effect of them on the rider's ABP. There are a lot of different connotations following a crash that can cause acute changes to an ABP, for example blood loss could cause a drop in haemoglobin with an accompanying rise in reticulocytes. Moreover, crashes can lead to riders being off their bikes for an extended period of time, especially if they've required surgery. A study looked at a number of elite athletes who had been forced to reduce their training over a 6 month period due to injury. It was discovered that during this time their haemoglobin concentration fell by $2.3 \%$, a significant enough amount to have an effect on the OFF-score and ABP (28). More significant than the reduction in training is the reduction in haemoglobin seen if the athlete also requires surgery. In this scenario, a reduction in haemoglobin concentration of $2.7 \%$ was recorded (28). These are clearly variables which the athlete would want to document on any anti-doping form.

\section{Dehydration}

Riding all day in hot weather leads to a huge amount of fluid loss, with some riders consuming as much as 10 litres of fluid per day during the Tour De France (29). If not adequately replenished, a rider can very quickly become dehydrated. Post-exercise or heat induced dehydration can cause an individual's plasma volume to drop by between 16-18\% (30). As haemoglobin and haematocrit levels are dependent on the total blood volume, reduced plasma volume through dehydration can cause these levels to appear raised. If a doping control blood sample is taken at this time, it may well appear abnormal due to changes in overall blood volume, rather than there actually being any changes in the blood components themselves (31). These changes are something that the rider has to keep in mind prior to any anti-doping samples being given, especially if they are required immediately after finishing a race or training ride, when dehydration is a greater risk.

Illness, especially involving diarrhoea and vomiting, can also cause dehydration. Although possibly not as acute as post-race dehydration, the effect is the same and it is therefore essential for riders to attempt to stay hydrated during times of illness. Weight loss can also accompany an illness, but studies have shown that this does not have any significant effect on haemoglobin (28).

Dehydration following heavy drinking sessions was the explanation given by former professional rider Jonathan Tiernan-Locke following a suspicious doping control blood sample in 2012. The sample showed high haemoglobin levels and low reticulocytes. TiernanLocke said that following the consumption of over 33 units of alcohol in six hours, he felt too unwell the next day to drink any water leading to extreme dehydration. However this explanation was rejected by UK AntiDoping and Tiernan-Locke was banned for two years (32).

\section{Stage Races}

A cycling stage race is one that consists of more than one day of riding, where the overall winner is the rider who completes all the days in the lowest cumulative time. These races include cycling's three Grand Tours; the Tour de France, Giro d'Italia and Vuelta a España. Each of these races last 3 weeks, racing over 100 miles most days, involving stages at altitude and, most probably, heat. Even if all goes to plan for a rider and they don't fall off, they will still experience all the other aspects 
mentioned above, that can affect their ABP. These big races are also one of the most likely times for a rider to be tested, however evidence of what normally happens to a rider's blood profile during this time is hard to come by. It is known that during the first few days of a stage race haemodilution can occur, therefore a drop in haemoglobin is expected, but little more is known (33). The main reason little is known on $\mathrm{ABP}$ changes during stage races is the requirement to take multiple blood samples from a rider to monitor what is happening to their blood profile. With the history of blood doping within the sport, there is reluctance on many sides for there to be needles and blood products around any team in case doping is suspected. Indeed the UCI currently have a 'no needle' policy (34) which would restrict any such testing during multiple-stage races. If a method could be found without the use of repeated needles, was accurate and universally accepted, it would be a big step for the sport and accuracy of the ABP to understand the normal physiological response to the stresses of a long stage race.

\section{Conclusion}

The aim of this article was to explain the rationale behind the $\mathrm{ABP}$, describe its components and review natural variations within it. The rationale behind the ABP is clear - to try and find a better method of detecting doping in sport. This appears to have been a success, especially with regards to two of the major forms of doping; rHuEPO and blood transfusions. Indeed it remains the only system available to detect autologous blood transfusions. Through this new style of indirect detection, the UCI can now punish those doping without any clear evidence on what they have used to dope. This also helps to erode the gap between a new doping substance or method entering the peloton and the detection test being created. This means the UCI are in a stronger position to catch those doping, no matter what substance(s) they are using. The UCI's position with regards to this will continue to be strengthened with the introduction of the Steroid Profile and increased experience with the blood profile. Also as WADA and the UCI get more experience with the ABP, it will become fairer for all athletes. The fact individual parameters are used does help make the passport fair for all athletes, regardless of genetic background, despite the original parameters being based on a white, European athlete. This does mean the first few tests for a new athlete may incorrectly fall outside confidence intervals. All of this by no way means the ABP is perfect. Overall, it is felt that the ABP is a huge advancement in anti-doping technology, but it is far from the finished product and further work is required in determining the 'natural' variation of the ABP during multiple-stage road races, such as the Grand Tours. As experience with the ABP increases and new areas are included, it will continue to grow as a deterrent to those wanting to cheat. What the ABP has done is reduce the advantage those doping achieve over clean riders, meaning clean riders can compete and have an equal chance of being successful.

\section{References}

1. World Anti-Doping Agency. World Anti-Doping Code. Montreal: WADA; 2015.

2. Cycling Weekly. Encyclopedia of doping in cycling Cycling Weekly. [Internet] 2019 [cited 25 Oct. 2019]. Available from: https://www.cyclingweekly.com/news/latestnews/encyclopedia-of-doping-74006

3. Marty D, Nicholson P, Haas U. Cycling Independent Reform Commission. Lausanne: UCI; 2015.

4. Haile D, Durussel J, Mekonen W, Ongaro N, Anjila E, Mooses M, et al. Effects of EPO on Blood Parameters and Running Performance in Kenyan Athletes.. Medicine and science in sports and exercise 2018; Sept.

5. USADA U.S. Postal Service Pro Cycling Team Investigation. Statement From USADA CEO Travis T. Tygart Regarding The U.S. Postal Service Pro Cycling Team Doping Conspiracy [Internet]. 2012 [cited 6 June 2015]. Available from: http://cyclinginvestigation.usada.org/

6. Union Cycliste Internationale. The Athlete Biological Passport - ABP [Internet]. 2014 [cited 6 June 2015]. Available from: http://www.uci.ch/clean-sport/theathlete-biological-passport-abp/

7. CADF. CADF releases its 2018 Business Report. [Internet] 2019 [cited 25 Oct. 2019]. Available from: https://www.cadf.ch/cadf-releases-its-2018-businessreport/.

8. UCI. UCI Clean Sport. [Internet] 2019 [cited 23 October 2019]. Available at: https://www.uci.org/docs/defaultsource/clean-sport-documents/adrv/2019-02-12sanction-adrv-eng-2-0.pdf?sfvrsn=3ab4874a_96.

9. World Anti-Doping Agency What is Prohibited. 2019 List of Prohibited Substances and Methods [Internet] 2019 [cited 2 July 2015]. Available from: https://www.wada-ama.org/en/content/what-isprohibited

10. Zorzoli M, Pipe A, Garnier P, Vouillamoz M, Dvorak J. Practical experience with the implementation of an athlete's biological profile in athletics, cycling, football and swimming. British Journal of Sports Medicine. 2014;48(10):862-866.

11. Segura J, Lundby C. Blood doping: potential or blood and urine sampling to detect autologous transfusion. $\mathrm{Br} \mathrm{J}$ Sports Med 2014;48:837-841

12. 2015 UCI Anti-Doping Regulations. UCI Testing \& Investigations Regulations. Aigle: UCI; 2015

13. UCI RTP List/ Liste 2019 [Internet]. 2019 [cited 10 January 2019]. Available from: https://www.uci.org/docs/default-source/uci-rtp/2018registered-testing-pool.pdf?sfvrsn=4ab6a36e_24

14. Pottgiesser T, Schumacher Y. Current strategies of blood doping detection. Analytical and Bioanalytical Chemistry. 2013;405(30):9625-9639.

15. Anti-Doping Research. EPO Test [Internet]. 2008 [cited 2 July 2015]. Available from: http://www.antidopingresearch.org/EPOtestJuly08.pdf

16. myDr Full Blood Count (FBC) [Internet]. 2017 [cited 23 October 2019]. Available from: https://www.mydr.com.au/tests-investigations/fullblood-count-fbc

17. Zorzoli M. Biological Passport Parameters. Journal of Human Sport \& Exercise. 2011;6(2):205-217.

18. Gore C. et al. Second-generation blood tests to detect erythropoietin abuse by athletes. Sports Hematology. 2003;88(3):333-344. 
19. UKAD. Anti-Doping Fact Sheet. London: UKAD; 2014 p. 2.

20. Higher Peak. Altitude-Oxygen Chart [Internet]. 2015 [cited 3 July 2015]. Available from: http://www.higherpeak.com/altitudechart.html

21. Vancouver First Aid. Affects of Altitude on the Human Body [Internet]. 2012 [cited 3 July 2015]. Available from: http://vancouverfirstaid.ca/affects-of-altitude-on-thehuman-body/

22. Chapman R, Stray-Gundersen J, Levine B. Epo production at altitude in elite endurance athletes is not associated with the sea level hypoxic ventilatory response. Journal of Science and Medicine in Sport. 2010;13(6):624-629.

23. Bonne T, Lundby C, Lundby A, Sander M, Bejder J, Nordsborg N. Altitude training causes haematological fluctuations with relevance for the Athlete Biological Passport. Drug Test Analysis. 2014

24. Scheinfeldt, L, Soi, S, Thompson, S, Ranciaro, A, Woldemeskel, D, Beggs, W, Lambert, C, Jarvis, J, Abate, D, Belay, G and Tishkoff, S. Genetic adaptation to high altitude in the Ethiopian highlands. Genome Biology. 2012;13(1), p.R1.

25. Beall C. Andean, Tibetan, and Ethiopian patterns of adaptation to high-altitude hypoxia, Integrative and Comparative Biology, Volume 46, Issue 1, February 2006, 18-24.

26. Smartertravel.com. Altitude of Bogota and Other Warning and Dangers [Internet]. 2017 [cited 25 October 2019]. Available from: https://www.smartertravel.com/altitude-bogota-warningdangers/

27. Beall C. Andean, Tibetan, and Ethiopian patterns of adaptation to high-altitude hypoxia. Integrative and Comparative Biology. 2006;46(1):18-24.

28. Gough C, Sharpe K, Garvican L, Anson J, Saunders P, Gore C. The Effects of Injury and Illness on Haemoglobin Mass. International Journal of Sports Medicine. 2013;34(09):763-769.

29. Otesports.co.uk. The Nutrition of a Tour de France Rider - OTE Sports [Internet]. 2015 [cited 10 July 2015]. Available from: http://www.otesports.co.uk/blog/post/the-nutrition-of-atour-de-france-rider/

30. Costill D, Fink J. Plasma volume changes following exercise and thermal dehydration. Journal of Applied Physiology. 1974;37(4):521.

31. Walker H, Hall W, Hurst J. Clinical methods. Boston: Butterworths; 1990.

32. Wynn N. Jonathan Tiernan-Locke blamed biological passport anomaly on binge drinking session - Cycling Weekly [Internet]. Cycling Weekly. 2014 [cited 11 July 2015]. Available from: http://www.cyclingweekly.co.uk/news/latestnews/jonathan-tiernan-locke-blamed-biologicalpassport-anomaly-binge-drinking-session-133330

33. Schumacher Y, Saugy M, Pottgiesser T, Robinson N. Detection of EPO doping and blood doping: the haematological module of the Athlete Biological Passport. Drug Test Analysis. 2012;4(11):846-853.

34. UCI Cycling Regulations, Part 13 Medical Rules. Aigle: UCI; 2015 p. 21. 